\title{
A COMPARATIVE STUDY OF THE ENGLISH VERSIONS OF LI HE'S POEM “THE SONG OF THE YANMEN GATE” ON COGNITIVE CONSTRUAL
}

Pan Zhenxiao

Graduate Student, School of Foreign Studies, Yangtze University, Hubei Province,

China

\begin{abstract}
:
Cognitive linguistics is based on the philosophy of experience, that is, human's cognitive activities are based on their own experience. Translation is a cognitive activity as well in which different translators are influenced by the four dimensions: scope and ground, perspective, prominence and specificity. Due to the four factors different understanding of the same scene will occur in the process of translation, resulting in diverse versions. This article attempts to study the dissimilarity in the English translation of "The Song of the Yanmen Gate" from the perspective of cognitive linguistics, in order to provide a new cognitive basis for interpretation of the differences among various English translation of poems.
\end{abstract}

Keywords: Construal; The Song of the Yanmen Gate; Tang poetry translation

\section{Introduction}

Tang Dynasty is known as the "Golden Age" of poetry. Tang poetry is the pinnacle of classical Chinese poetry and one of the precious cultural heritages of the Chinese nation. Li He was a romantic poet in the Mid-Tang Dynasty, together with Li Bai and Li Shangyin called "the Top Three Li" of the Tang Dynasty. His poetry style is the representative of the transition period from Mid-Tang to Late Tang.

Translation (including poetry translation) is an activity of inter-language transformation. In a way, it is the same as telling stories which explains the contents of one language in another language. In this story-telling process or the process of poetry translation, the translator first understands the original poem such as the content and background knowledge of the poem, which is "scope and ground" in cognitive linguistics; after the scope and ground of poetry are determined, it is necessary to study what perspective of the poem is arranged, that is, whether the poet is in the scene or outside the scene; In addition, we must also take this into account: Where is the focus or the essence of poetry? Because of the differences between the two languages, the content of interpretation cannot be exhausted; finally, attention should be paid to

iCorrespondence: email 954220623@qq.com 
the specify about how detailed the storyteller should deliver. The four aspects mentioned above are the theoretical framework of construal in cognitive linguistic. In this paper, we will use the construal theory to examine the differences between the three English versions of "The Song of the Yanmen Gate", aiming at providing a new cognitive basis for the diversity in the English translation of poems.

\section{Construal theory and its four dimensions}

Construal is a vital theoretical concept in cognitive grammar, first proposed by Langacker and defined as the way of human beings interpreting the same scene. It was originally called "imagery", with three dimensions of selection, perspective and abstraction (Langacker, 1987). Later, Langacker (1991) further classified it into: scope, ground, perspective, prominence and specificity. After that, the classification was further improved, the scope and background were merged (Langacker, 2008), and the theory of Construal was reduced to four dimensions, which are independent and complementary to each other. The following is an explanation of the four dimensions of Construal.

\subsection{Scope and ground}

Wang Yin (2008) pointed out that scope refers to the allocation of related concepts and background knowledge activated by expressions people use in describing things. Langacker (1987) believes that cognitive domains can be divided into basic domains and abstract domains. The former includes three-dimensional space, taste, color, sense of touch, etc., while the latter refers to any complex concept, such as the human body, chess, friends and family network, etc. In the process of poetry translation, the translator will first cognize the original poem, and then activates the content and background knowledge of the poem, such as the poet's social background, life story and poetry style.

\subsection{Perspective}

Perspective is the angle from which people observe an object or scene, reflecting the relative relationship between the observer and the observed object or scene. Visual angle is of great significance to semantics. Because observing things from different angles could produce totally different results such as different language expressions in language translations. After knowing the general ground knowledge, for poetry translation, translators do their job from the perspective the poet, that is, whether the poet himself is in the scene or the poet is outside the scene, because different perspectives reflect different emotions.

\subsection{Prominence}

When people describe an event or scene, their language expression structure is always asymmetric. This is because the observer will give prominence to his own attention when expressing his language. Due to the differences between the two languages, the translation and the original poem are not completely equivalent. As a result, it is necessary to consider the key points or the essence of poetry after understanding the background and perspective of poetry. 


\subsection{Specificity}

The words and phrase used in the translations imply how detailed the translator demonstrates. The level of detail can express decreases gradually, which is equivalent to the upper and lower meanings in choosing words such as: thing $>$ object $>$ pen. The more detailed the language displays, the narrower the scope of construal is, and vice versa. The lower the level of detail in the translation equals the more information translated, in other word, more similar to the original poem. Many scholars apply the theory of construal to poetry translation research, which can be roughly divided into two categories: one is based on the complete theoretical framework (Tan Yesheng, 2009) while the other is based on part of this theory. This paper will follow the former to achieve poetry translation research.

\section{An introduction to "the Song of the Yanmen Gate"}

"The Song of the Yanmen Gate" is a poem written by Li He, a poet of Tang Dynasty, describing the war scenes by using the inscription of ancient Yuefu. Most of the poems he wrote lamented his unfortunately life and the inner distress or reflected the separatism of the vassal, the cruel exploitation of the people. This poem depicts the solemn and stirring fighting scenes with rich mottled colors. Bizarre picture in this poem accurately show the frontier scenery and the everchanging war situation at a specific time and place. In this paper, three English versions from "Three Hundred Tang Poems" by Xu Yuanchong (trans.), "From Poetry to Poems: An English Translation of classical Chinese Poems" by Ren Zhiqi \& Yu Zheng (trans.), and "Gems of Chinese Poetry" by Ding Zuxin (trans.). The original reads like this:

\section{黑云压城城欲摧,} 甲光向日金鳞开。 角声满天秋色里, 塞上燕脂凝夜紫。 半卷红旗临易水, 霜重鼓寒声不起。 报君黄金台上意， 提携玉龙为君死。

\section{A comparative study of the three English versions of "the Song of the Yanmen Gate"}

\subsection{Scope and ground}

Li He was weak and sick since childhood, and his career was not smooth as an adult. He lived in the middle Tang Dynasty after the "An Lushan Rebellion" when the regime of Tang Dynasty declined, and the society was in turmoil together with constant wars. It is in this social background that Li He intoned "the Song of the Yanmen Gate" which praised the determination of the imperial soldiers to serve the emperor by describing their heroic resistance against the enemy. Therefore, this poem has a desolate artistic conception, a solemn and stirring style, a strong shock and artistic charm. 
(1) 黑云压城城欲摧, 甲光向日金鳞开

Xu: Dark clouds over the town threaten to crush it down;

Like golden scales the armor glistens in sunlight.

Ren \& Yu: Black clouds loom heavy over the city,

And the city on the verge of caving in, armors gleam golden with open scales in the sun.

Ding: Black clouds hang heavy across the city as if to overwhelm city and daylight together.

The General's chain-mail glitters,

Metal scales gaping open.

The first pair of couplet is about the scenery of the war, which exaggerating the tense atmosphere and critical situation of the soldiers approaching the city, and showing the strong defenders by sunlight. If the translator translates the "黑云 heiyun" in this sentence as a powerful enemy, then he does not really understand the scope and ground of this poem. Because the background of this sentence shows the sense of crisis under the enemy, the "Black clouds" by the three translators all highlights the sense of oppression and tension: Dark clouds in Xu's, Black clouds in Ren \& Ding's. In this scene of war, Li He intended to express his praise to the soldiers which can be seen from an extraordinary contrast of color in the poem (dark to bright). $\mathrm{Xu}$ translation: black, down, gold, listening; Ren and Yu translated: black, loom, weight, shimmer, gold, open; Ding translation: Black, Heavy, Glowing. When deconstructing the original and constructing a translation of the same literary work, due to the differences of translators' cultural background, social background and knowledge reserves, the translation will show differences, which are manifested in the different language expression at the language level $(\mathrm{Lu} \mathrm{Yu}, 2018$ : 114). As this poem describes the war scene, the translator activated the words such as "threat" and "crush it down" in Xu's translation to describe the cruel scenes of the war scene.

\subsection{Perspective}

After determining the scope of the description, we should consider from which angle we can observe, which involves the position of the observer, direction and angle of observation, as well as the narrative and the subject.

（2）报君黄金台上意，提携玉龙为君死。

Xu: To fulfill the sovereign's Golden Tower dream, Jade dragon sword in hand, they'd die without a word.

Ren \& Yu: To return the favor on the Golden Stage,

I tote my Yu long sword to die for him.

Ding: But for all you gave us

At the Golden Tower,

We will fight for Your Majesty,

We will die for Your Majesty,

Through fire and through water. 
There are two explanations for this sentence. One is to praise the soldiers' determination to serve the country to the death, and the other is to express the poet's ( $\mathrm{Li} \mathrm{He}$ ) strong feelings of serving the country as soldiers on a bloody battlefield. Therefore, the translator can choose different angles to interpret. Xu's translation uses the third person, while Ren's and Yu's translation and Ding's translation both choose the first person. The choice of different characters shows that the translator perceives poetry from different angles and with different feelings, as a result that the expression and purpose of the translated poetry also vary. The first-person perspective is more expressive, so the reader is closer to the original author and easier to enter the psychological world of the original author, while the third-person emotion expression is weaker in the delivery of emotion.

\subsection{Prominence}

(3) 半卷红旗临易水, 霜重鼓寒声不起。

Xu: With red flags half furled up, our troops come near North Stream;

Muffled by heavy frost, their drumbeats can't be heard.

Ren \& Yu: Battle banners half-furled over the Yishui River,

Drums go mute from heavy frost and cold.

Ding: Scarlet flags half furled,

Our army advanced to the River Yi.

In the heavy frost, the cold air,

Our drums beat dull, low.

This sentence is the second line of poetry, describing the scenes of night battles and bloody battles of troops. It is known that the focus of people's attention reflects what observers want to emphasize. Langacker distinguishes two main paths to highlight, that is, the combination of trajector and landmark. In this sentence, Xu's trajector is "our troops", the path is "come near", and the landmark is "North Stream"; Ren \& Yu's trajector is "Battle banners", and the path is "over", the landmark is "Yishui River". Ding's translation is similar to Xu's translation. The trajector is "Our army", the path is "advanced to" and the landmark is "Yi River". The trajector in Ren and Yu's versions is not the same as those in Ding's version. In other words, what Ding wants to highlight is quite unlike the other.

In addition, compared with "come next" and "advanced to", "over" which refers to path in cognitive cannot show the tension of soldiers attacking the enemy at night.

(4) 角声满天秋色里, 塞上燕脂凝夜紫。

Xu: Blowing up to the sky, horns take an autumn dye;

Rouge like blood on the frontier turns violet at night.

Ren \& Yu: Battle horns fill the sky of an autumnal hue,

Frontier rouge freezes into a nocturnal purple.

Ding: Bugles sound; autumn frost comes down.

At night dark blood on the ground Looks darker still. 
This sentence renders the tragic atmosphere of the battlefield and the cruelty of fighting from both auditory sense and visual sense. Xu's translation of "up to the sky" highlights the lightness of space in bottom-up direction. In the translation of Ren $Y u$ and $Y u$, the verb "fill" is used to express the feeling of bulging or floating in the air. While Ding uses "comes down" to highlight the heaviness of autumn frost in top-down direction. These different content of their choice results in the diversity in translators' translations.

\subsection{Specificity}

The display of details is usually embodied in the choice of words. In this part, some image words in poetry are selected for our study. Ding's translation of "金 鳞" as "Metal scales" is very different from Xu and Ren's "golden scales". In the poem, “金 鳞" is meant to express that the armor gleams like a golden jade, showing the bright colors of "golden", meanwhile, forming a strong color contrast with the black color in the "black cloud". “金鳞” in "Metal scales" of Ding's is more concise, that is, the expression level is "abbreviated". Ren and Yu's translation of Yishui River is more detailed, and there are allusions here: Yishui refers to "Yan Dan's farewell to Jing Ke's Lishui", and Ren and Yu's translation is closer to the original text. “黄金台” is an allusion of the platform built by King Zhao Yan in order to attract talents in Warring States Period. Gold and white jade weights for their texture and color. Dragon is a noble animal in ancient legends. “黄金台” is a symbol of longing for talents. The "stage" in the Golden Terrace translated by Ren and $\mathrm{Yu}$ is not as detailed as in the Golden Tower translated by Ding, which brings difficulties and even misunderstandings to the readers. “玉龙" was used to call swords in Tang Dynasty. $\mathrm{Xu}$ 's translation is more detailed: "Jade dragon sword", because Yulong is not as representative as "Yi Shui"; the transliteration of Ren \& Yu's translation cannot fully show the content expressed in the original poem; Ding just ignore it. If there is no annotation to understand, then the translated poem will lose some of the meaning expressed in the original poem.

\section{Conclusion}

The above examples show that different ways of construal of the same source text will cause different versions of target language, which is reflected in the difference in word selection and sentence making at the linguistic level. Therefore, in this sense, the cognitive perspective of cognitive linguistics provides a new perspective to reveal and explaining the differences between different versions of the same text. Langacker (1987) defines cognition as the conceptualization of a person's own experience. Poetry translation under the guidance of cognitive theory pays more attention to the impact of the translator's subjectivity on translation and equivalence of meaning in translation. However, compared with other texts, poetry translation has its own particularity. The genre, rhythm and structure of poetry are unique and aesthetic. Therefore, the process of poetry translation under cognitive theory does not take into account the influence of poetry form and readers' feelings. 


\section{References}

[1] Langacker, R. Foundations of Cognitive Grammar: Theoretical Prerequisites. California: Stanford University Press, 1987.

[2] Langacker, R. Foundations of cognitive grammar: Descriptive application. Stanford, California: Stanford University Press, 1991.

[3] Langacker, R. Cognitive grammar: A basic introduction. Oxford: Oxford University Press, 2008.

[4] Liao, X. The Application of Cognitive Linguistic Theories to English-Chinese Translation. Open Journal of Modern Linguistics, 2018: 61-69.

[5] Tao, S. On Poetry Translation from Cognitive Construal Perspective: A Case Study of the English Versions of Chinese Ancient Poem Tian Jing Sha. Qiu Si. International Journal of Publication and Social Studies, 2019: 37-47.

[6] Lu, Y. A Comparative Study of English Translation of Du Fu's Poem “View from a Height in the Perspective of Cognitive Construal. Overseas English, 2018:144-145.

[7] Tan, Y. Construal across Languages: A Cognitive Linguistic Approach to Translation. Shanghai: Shanghai Foreign Language Education Press, 2009.

[8] Tan, Y. A Construal-centered Cognitive Approach to Understanding Translation Competence. Chinese Translators Journal, 2016:15-22+128.

[9] Wang, Y. The interpretation of subjectivity-objectivity in translation by means of "Embodied Conceptualization"-An analysis of 40 English translations of "Night Mooring by Maple Bridge". Foreign Language Teaching and Research, 2008: 211 -217.

[10] Wang, Y. Cognitive Translation Studies. Chinese Translators Journal, 2012: 17-22.

[11] Wang, Y. Cognitive Linguistics. Shanghai: Shanghai Foreign Language Education Press, 2011. 

to their work. Under the terms of this license, no permission is required from the author(s) or publisher for members of the community to copy, distribute, transmit or adapt the article content, providing a proper, prominent and unambiguous attribution to the authors in a manner that makes clear that the materials are being reused under permission of a Creative Commons License. Views, opinions and conclusions expressed in this research article are views, opinions and conclusions of the author(s). and European Journal of Literature, Language and Linguistics Studies shall not be responsible or answerable for any loss, damage or liability caused in relation to/arising out of conflicts of interest, copyright violations and inappropriate or inaccurate use of any kind content related or integrated into the research work. All the published works are meeting the Open Access Publishing requirements and can be freely accessed, shared, modified, distributed and used in educational, commercial and non-commercial purposes under a Creative Commons Attribution 4.0 International License (CC BY 4.0). 